\title{
GENERATION OF NATURAL CONVECTIVE AIR FLOWS IN ROOMS WITH THE USE OF IN-FLOOR CONVECTORS WITH NATURAL CIRCULATION
}

\author{
Viktor Pukhkal ${ }^{1}$, Vadim Bulgakov ${ }^{2}$ \\ 1,2 Saint Petersburg State University of Architecture and Civil Engineering \\ Vtoraja Krasnoarmejskaja ul. 4, St. Petersburg, Russia \\ 1 pva1111@rambler.ru
}

\begin{abstract}
To prevent the intake of downward cold air flow from translucent structures into the room serving area, convectors with natural convection, embedded in floor construction, are used.

Convector operation was simulated at various distances from the glazing to the convector with ANSYS Fluent 14.5 program. Temperature and velocity fields inside the room were determined.

Natural convective flows in the room (downward cold air flow at the glazing and upward warm air from the convector) were described. Application conditions of in-floor convectors with natural air circulation were determined.
\end{abstract}

\author{
Keywords \\ Heating, residential and public buildings, in-floor convector, natural convection.
}

\section{Introduction}

Glazed window openings represent a source of discomfort for people inside the building due to the generation of downward cold air flows at the glazing and their intake into the room serving area. Use of heating units in the form of convectors with natural or forced air circulation, embedded in floor construction (in-floor convectors), is one of the solutions preventing cold air intake (Krupnov and Krupnov, 2010; Mayorov, 2014; Makhov, 2014; composite author, 2012; "VITATERM", 2008; Babiak et al., 2013). The convector is located directly at the glazing or at a distance of $80-350 \mathrm{~mm}$ from it.

To develop a procedure for engineering of water heating systems with in-floor convectors, it is necessary to get an overview of interaction between two air flows: the downward cold air flow at the glazing and the upward warm air flow from the heating unit.

Figure 1 presents the data of experimental studies of the glazing temperature influence on the generation of flows coming from the fan convector embedded in floor construction (convector with forced air circulation), and a qualitative picture of the air flows movement at the convector inlet and outlet (Muller M. et al., 2013).

A conclusion of the insignificant influence of glazing cooling in the measured area on the movement of the adhering air flow from the convector fan was made. However, it does not mean that this effect cannot occur at a higher vertical position.

The heat flow from the convector was experimentally determined and the pattern of air flows and temperature fields was simulated for the room with a convector with natural convection (Bašta and Legner, 2017).

It was established that the radiation component of the heat flow was less than $1 \%$. The mathematical simulation of temperature and velocity fields for the room with the area of $4 \times 4 \times 2.6 \mathrm{~m}$ and window dimensions of $2 \times 2.4 \mathrm{~m}$ was performed (Figure 2). 


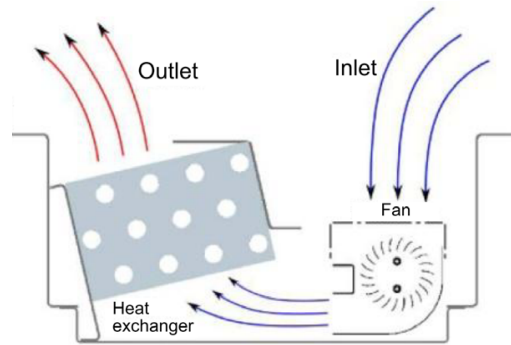

(A)
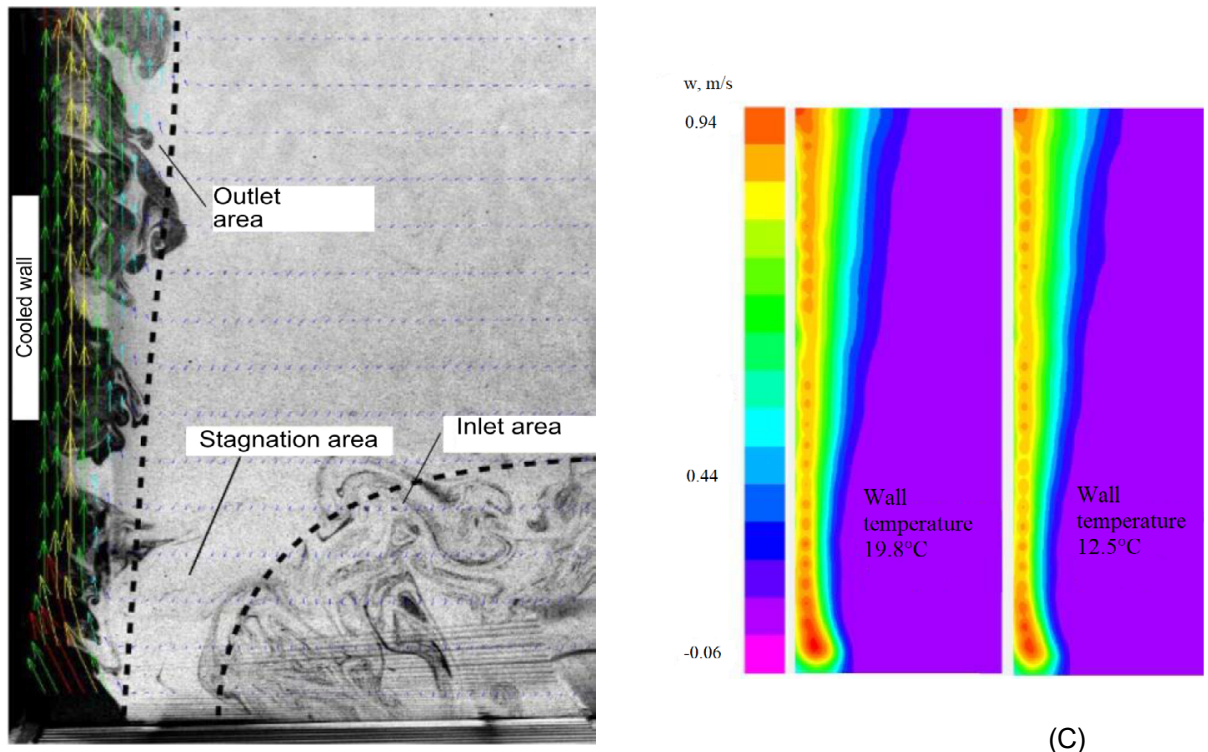

(C)

(B)

Figure 1. Air flow patterns during fan convector operation:

A - fan convector principle; B - air flow patterns; C - comparison of vertical velocity components for temperatures

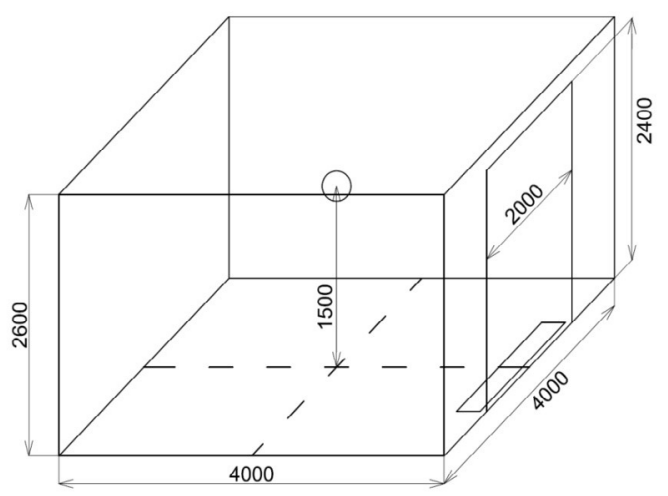

(A)

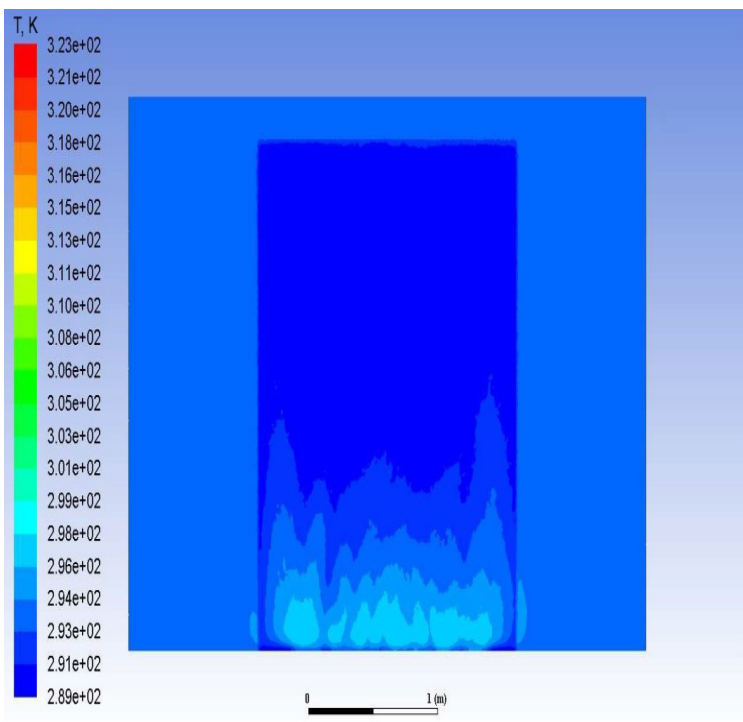

(C)

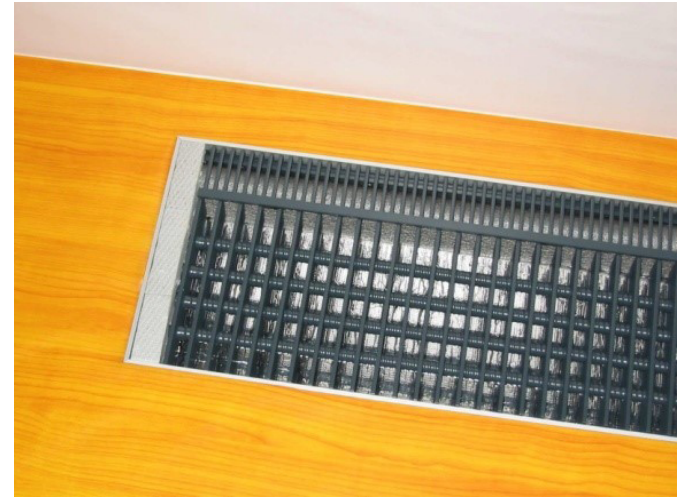

(B)

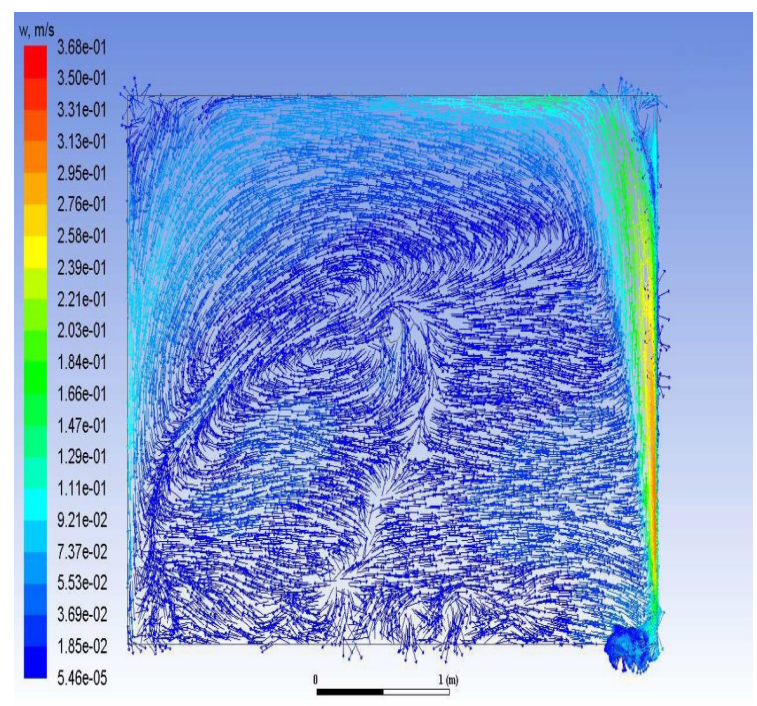

(D)

Figure 2. Design model of the room and results of temperature and velocity field studies:

A, B - design model of the room and the studied convector; C - temperature field of the internal surface of the external wall and glazing; $\mathrm{D}$ - velocity field at section along the convector axis in a plane perpendicular to the window 
A BITHERM Floor convector with natural convection (dimension: $2000 \times 245 \times 55 \mathrm{~mm}$ ) was installed at a distance of $70 \mathrm{~mm}$ from the glazing. The specific heat flow on the glazing surface is equal to $38.4 \mathrm{~W} / \mathrm{m}^{2}$, and on the surface of the external wall it is equal to $8 \mathrm{~W} / \mathrm{m}^{2}$. The temperature at the surface of the heating element was assumed to be $50^{\circ} \mathrm{C}$.

Taking into account simulation conditions, it was established that the heated air flow from the convector was adhering to the glazing surface (Figure 2). In the upper part of the room, an enclosed circulation area with the downward cooled air flow is generated upon air flow turning and adhering to the ceiling (Smirnov et al., 2017).

This study allows concluding that the convective flow from the convector, progressing at the vertical cooled barrier (glazing), shows a tendency to adhering. The adhering of convective flows has been understudied. Therefore, the study objective is to obtain qualitative characteristics related to the progressing of convective flows depending on the distance between the glazing surface and the convector (Vasiliev, 2017).

\section{Methods}

To account the actual operating conditions of the convector embedded in floor construction and for a detailed study of distribution of velocity and temperature fields inside the room, convector operation was simulated with ANSYS Fluent 14.5 program.

A room with the dimensions typical for residential and public buildings was adopted as a model: width $-3 \mathrm{~m}$; depth $-6 \mathrm{~m}$; height $-3 \mathrm{~m}$ (Figure 3). The window dimensions $-3 \times 3 \mathrm{~m}$. A KRKP-1.058-128 convector (OJSC "Izoterm", Russia) was simulated (VITATERM, 2008). The convector is located at a distance of $100 \mathrm{~mm}$ from the glazing.

In simulation, the following conditions were preset:

- temperatures on the internal surfaces (side walls, floor, ceiling) - plus $18^{\circ} \mathrm{C}$;

- outside air temperature - minus $24^{\circ} \mathrm{C}$;

- heat transfer coefficient of the external surface of the glazing $-23 \mathrm{~W} /\left(\mathrm{m}^{2} \mathrm{~K}\right)$;

- heat transfer coefficient of the internal surface of the glazing $-8 \mathrm{~W} /\left(\mathrm{m}^{2} \mathrm{~K}\right)$;

- average thermal resistance of the glazing -0.685 $\left(\mathrm{m}^{2} \mathrm{~K}\right) / \mathrm{W}$;

- temperature on the surface of the heating element $-64.5^{\circ} \mathrm{C}$

- location of the heating element of the convector - in the center of the box.

\section{Results}

The calculation results for velocity and temperature fields in the room, obtained at various distances from the glazing to the convector $(\mathrm{l}, \mathrm{mm})$, are presented in Figures 4 and 5 . Based on these calculations, it is possible to evaluate the nature of the interaction between the downward flow at the glazing and the upward flow coming from the convector provided the heat flow from the convector is equal to heat losses through the glazing.

If the distance between the glazing and the convector is less than $400 \mathrm{~mm}$, the warm air flow adheres to the glazing throughout its height. At a distance of $400 \mathrm{~mm}$, three areas are generated at the internal surface of the window: a downward cold flow of natural convection (a cold air jet), a vortex area and a semi-restricted gravitational (warm) jet from the convector (Figure 4).
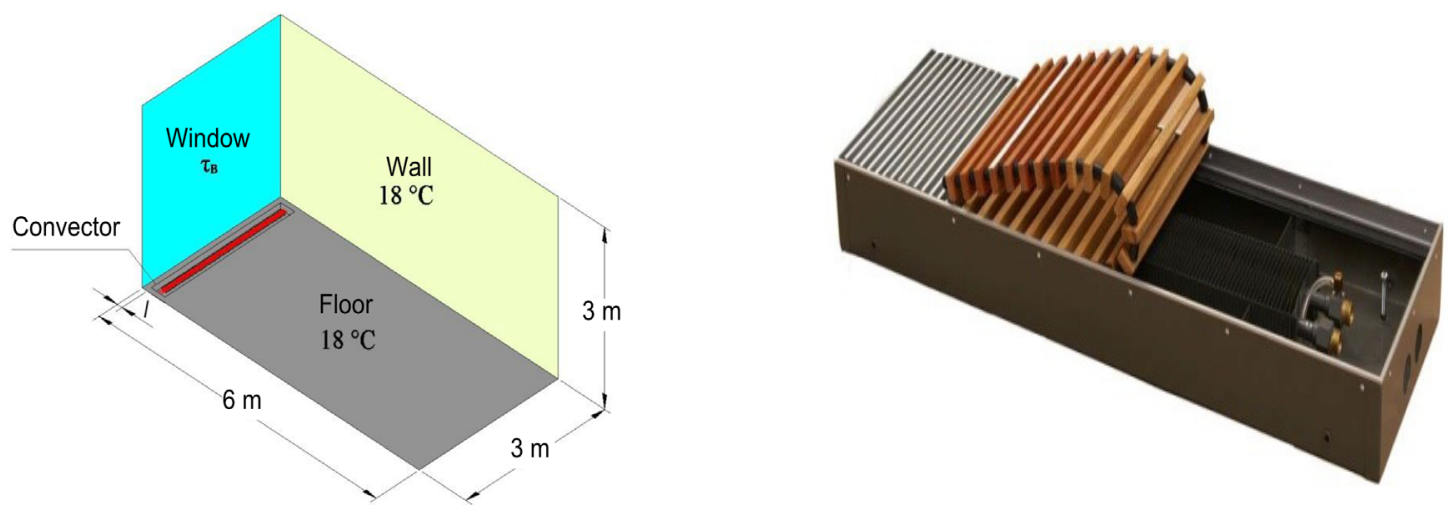

Figure 3. Design model of the room and the convector 
Viktor Pukhkal, Vadim Bulgakov — Pages 42-47

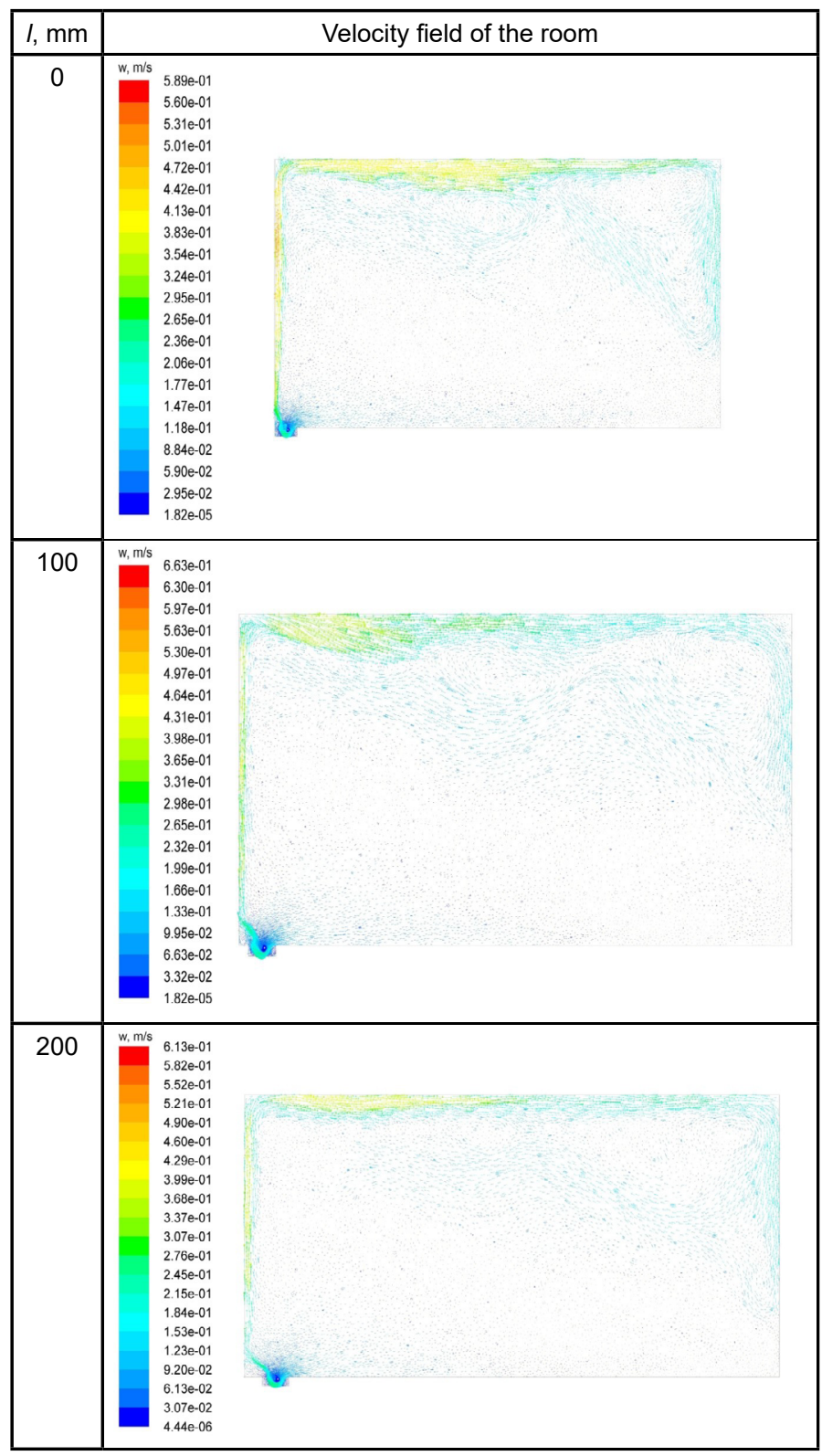

\begin{tabular}{|c|c|c|}
\hline $\mathrm{I}, \mathrm{mm}$ & & Velocity field of the room \\
\hline 300 & 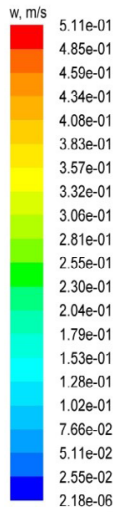 & $=0$ \\
\hline 400 & 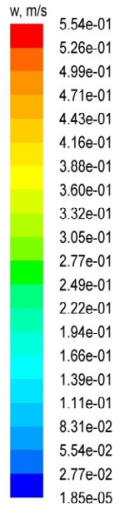 & V \\
\hline 1000 & 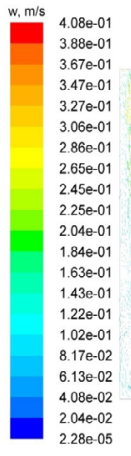 & 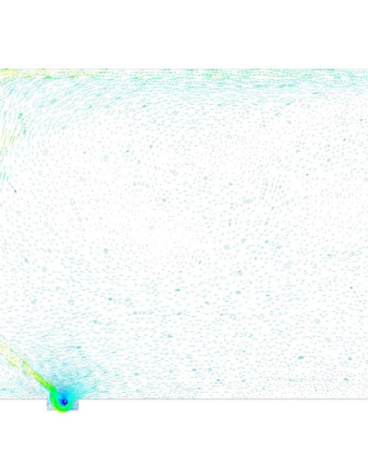 \\
\hline
\end{tabular}

Figure 4. Simulation results for velocity fields of the room (section along the room axis; a plane perpendicular to the window) 


\section{Architecture and Engineering Volume 2 Issue 4}
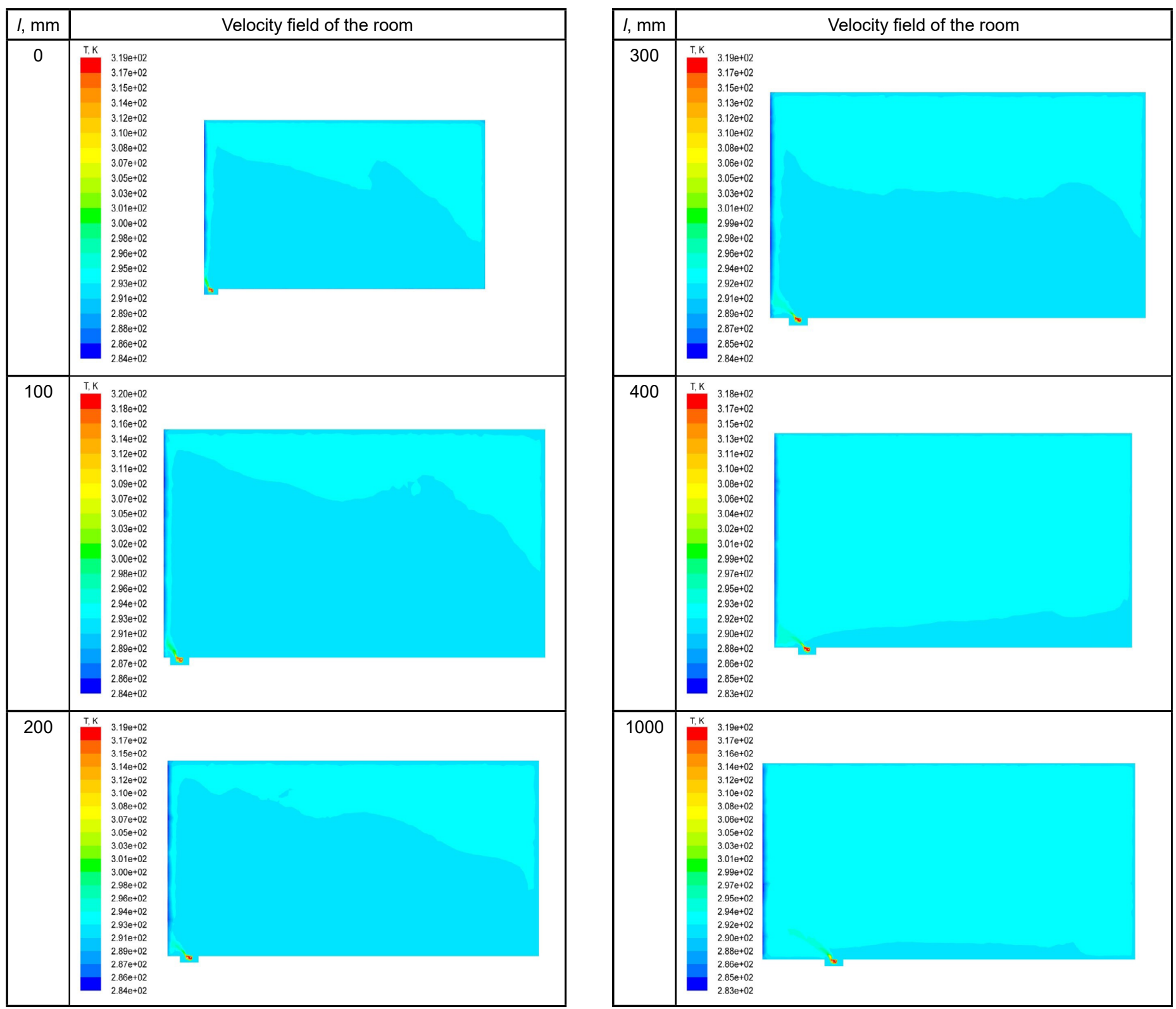

Figure 5. Simulation results for temperature fields of the room (section along the room axis; a plane perpendicular to the window)

In the vortex area, where the warm and cold jets merge, the direction of a newly formed jet changes sharply. The jet is deflected deep into the room. The merging area is located at $\sim 2.4 \mathrm{~m}$ from the floor.

The increase in the distance from the glazing to the convector to $1,000 \mathrm{~mm}$ results in the generation of two flows: a downward cold air flow throughout the entire glazing height, which is partially mixed with an upward heated air flow from the convector and enters the convector for heating, and an upward warm flow from the convector, which deflects towards the glazing.

The calculation data presented in Figures 4 and 5 show that the adhering convective jet from the convector ascends to the upper part of the room and an area of elevated temperatures develops, if the distance between the convector and the glazing is less than $400 \mathrm{~mm}$. Several enclosed circulation areas are formed instead of a single circulating air flow. The increase in the distance to 1,000 $\mathrm{mm}$ allows adjusting the temperature field in the room.

\section{Conclusions}

1. Convectors with natural circulation, embedded in floor construction, with a heat flow equal to heat losses through the glazing and located at a distance less then $400 \mathrm{~mm}$ from the glazing, form a convective jet adhering to the glazing and protecting the room from the downward cold flow at the glazing.

2. To eliminate the nonuniform heating of the glazing, the distance from the in-floor convector to the glazing should be at least $100 \mathrm{~mm}$.

3 . It is recommended to place the heating element of the in-floor heater with natural air circulation close to the box wall on the glazing side or in the center of the box. 


\section{References}

Babiak, J. (2013). Low temperature heating and high temperature cooling: embedded water based surface heating and cooling systems. Brussels: REHVA.

Basta, J., Legner, T. (2017). In-floor convector analysis. Prague: Czech Technical University in Prague.

Krupnov, B., Krupnov, D. (2010). Otopitel'nye pribory, proizvodimye v Rossii i blizhnem zarubezh'e [Heating devices made in Russia and neighboring countries]. Moscow: ASV. (in Russian)

Makhov, L. (2014). Otoplenie [Heating]. Moscow: ASV. (in Russian)

Mayorov, V. (2014). Peredacha teploty cherez okna [Heat transfer through windows]. Moscow: Izdatel'stvo ASV. (in Russian)

Muller, M., Frana, K., Kotek, M., Dancova, P. (2013). The influence of the wall temperature on the flow from the floor convector (experimental results). EPJ Web of Conferences, 45. DOI: 10.1051/epjconf/20134501130.

Otopitel'nye pribory i poverkhnosti [Heating devices and surfaces] (2012). Moscow: Akva-Term (in Russian)

Smirnov, E.B., Datciuk, T.A., Taurit, V.R. (2017). Estimation of ecological safety of the designed buildings. Water and Ecology, 3, pp. 82-99. DOI: 10.23968/2305-3488.2017.21.3.83-99

Vasiliev V. F. (2017). Ecological influence of industrial buildings with aeraty on the quality of city air. Water and Ecology, 4, pp. 70-75. DOI:10.23968/2305-3488.2017.22.4.70-75

VITATERM (2008). Rekomendatsii po primeneniyu konvektorov "Gol'fstrim" ("Izoterm-TD"), vstraivaemykh v konstruktsiyu pola [Recommendations for use of "Gol'fstrim" ("Izoterm-TD") convectors which are built into the floor construction]. Moscow: VITATERM. (in Russian) 